\title{
A Method of Synthesizing Lithium Hydroxide Nanoparticles Using Lithium Sulfate from Spent Batteries by 2-Step Precipitation Method
}

\author{
Soyeong Joo, Hyun-Woo Shim, Jin-Ju Choi, Chan-Gi Lee, and Dae-Guen Kim* \\ Materials Science and Chemical Engineering Center, Institute for Advanced Engineering (IAE), Yongin 17180, Republic of Korea
}

\begin{abstract}
In this work, $\mathrm{LiOH}$ was synthesized using highly soluble $\mathrm{Li}_{2} \mathrm{SO}_{4}$. To enhance efficiency, this synthesis was performed using the precipitation method, and the correlation between each experimental condition and the synthesis of $\mathrm{LiOH}$ was investigated. The particle size and crystalline properties were tailored by controlling various experimental conditions, including the mole ratio of $[\mathrm{Li}] /[\mathrm{OH}](\mathrm{Li}$ : lithium sulfate, $\mathrm{OH}$ : barium hydroxide), reaction temperature, and reaction time. First, precursors with a ratio of 1:0.5 were reacted for $60 \mathrm{~min}$ at a solution temperature of $40{ }^{\circ} \mathrm{C}$ and filtered to remove precipitates. For the double reaction, half the hydroxyl precursor was added to the filtered solution and reacted under the same conditions. Using two-step precipitation, we were able to synthesize powder with a pure LiOH phase, a particle mean size of $100 \mathrm{~nm}$, and purity over $99 \%$.
\end{abstract}

(Received November 18, 2019; Accepted February 14, 2020)

Keywords: LIBs, lithium hydroxide, lithium sulfate, precipitation, nanoparticles

\section{INTRODUCTION}

High purity lithium hydroxide $(\mathrm{LiOH})$ is a widely used industrial chemical, in catalysts [1,2] and as a carbon dioxide absorbent [3,4]. In particular, it is used as a positively charged electrode material and as an electrolyte in lithium ion batteries $[5,6]$. Due to the rapid increase in the usage of Licontaining products in electric vehicles, a substantially equivalent amount of lithium waste is also produced. Numerous attempts have been made to recycle lithium waste, which has resulted in the recovery of lithium precursors [710]. However, the recovered $\mathrm{Li}$ contains other impurities such as magnesium, calcium, and nickel, which makes it difficult to synthesize high purity $\mathrm{LiOH}$. A synthetic method of recovering $\mathrm{Li}$ from recycled lithium precursors would be highly valuable.

Among the various methods that have been studied to synthesize $\mathrm{LiOH}$, ion exchange and electrolysis have been the most commonly used due to their simplicity [11-16]. However, an ion exchange method using simple precipitation

- 주소영 · 심현우 · 최진주 · 이찬기 · 김대근: 연구원

*Corresponding Author: Dae-Guen Kim

[Tel: +82-31-330-7419, E-mail: dgkim@iae.re.kr]

Copyright (C) The Korean Institute of Metals and Materials is preferable to electrolysis, if it could be accomplished using specific equipment such as an exchange membrane and result in high purity.

$\mathrm{LiOH}$ is typically synthesized using a lithium carbonate $\left(\mathrm{Li}_{2} \mathrm{CO}_{3}\right)$ precursor. To date, few studies have employed lithium sulfate $\left(\mathrm{Li}_{2} \mathrm{SO}_{4}\right)$ for the same process. Because $\mathrm{Li}_{2} \mathrm{CO}_{3}$ has low solubility $\left(1.54 \mathrm{~g} / 100 \mathrm{~g}, 0{ }^{\circ} \mathrm{C}\right.$ water $)$ its conversion efficiency into $\mathrm{LiOH}$ is less than $60 \%$ in water, as reported in numerous papers. This is because $\mathrm{Li}_{2} \mathrm{CO}_{3}$ only reacts with a limited surface area by dissolution and ion exchange, and as a result, a mixed phase of $\mathrm{Li}_{2} \mathrm{CO}_{3}$ and $\mathrm{LiOH}$ co-exist in one solution [10].

In this study, we synthesized $\mathrm{LiOH}$ nanoparticles using recycled $\mathrm{Li}_{2} \mathrm{SO}_{4}$ from spent discarded $\mathrm{Li}$-containing products with $\mathrm{Ba}(\mathrm{OH})_{2}$. To enhance productivity, highly soluble $\mathrm{Li}_{2} \mathrm{SO}_{4}\left(26.1 \mathrm{~g} / 100 \mathrm{~g}, 0{ }^{\circ} \mathrm{C}\right.$ water $)$ and a barium hydroxide $\left(\mathrm{Ba}(\mathrm{OH})_{2}\right)$ precursor were chosen to prepare $\mathrm{LiOH}$ via a twostep precipitation method. We were able to achieve the complete conversion of the precursors into $\mathrm{LiOH}$ through the two-step precipitation method. $\mathrm{Ba}(\mathrm{OH})_{2}$ was selected due to its insolubility with $\mathrm{Ba}(\mathrm{SO})_{4}$, which was a byproduct, in water. The solution was evaporated to obtain $\mathrm{LiOH}$ powder, which in turn was used to analyze crystallinity and morphology. Precursor ratio, reaction time, reaction 
temperature and drying temperature were all evaluated to optimize the reaction conditions.

\section{EXPERIMENTAL PROCEDURE}

Initially, $0.01 \mathrm{~mol}$ of recycled $\mathrm{Li}_{2} \mathrm{SO}_{4}$ (Sungil Co., 99\%) precursor was put into $100 \mathrm{ml}$ of D.I water at room temperature (RT) and stirred at $300 \mathrm{rpm}$ for $20 \mathrm{~min}$ to be fully dissolved. Subsequently, the solution was heated between RT and $60{ }^{\circ} \mathrm{C}$ at an increasing speed of $5{ }^{\circ} \mathrm{C} / \mathrm{min}$. When the $\mathrm{Li}_{2} \mathrm{SO}_{4}$ precursor reached the set temperature value, $0.01 \sim 0.05 \mathrm{~mol}$ of $\mathrm{Ba}(\mathrm{OH})_{2}$ (Sigma Aldrich Co. 95\%) was added to the solution and reacted for 2 to 6 hours. After the reaction, the precipitates were removed, and the solution was evaporated to collect powder. For the complete conversion of the precursors, a two-step precipitation method was employed by adding equal amounts of D.I water, $\mathrm{Li}_{2} \mathrm{SO}_{4}$, and half of the above-mentioned $\mathrm{Ba}(\mathrm{OH})_{2}$ into the solution at $40{ }^{\circ} \mathrm{C}$ for $1 \mathrm{~h}$. The powders that precipitated were filtered and removed while the solution was left to react with the remaining $\mathrm{Ba}(\mathrm{OH})_{2}$ at the same conditions. After the reaction, the solution was filtered with a $450 \mathrm{~nm}$ microfilter. The filtered solution was further evaporated using a hot plate at a solution temperature between $70 \sim 90{ }^{\circ} \mathrm{C}$, until a white powder started to emerge.

In order to examine its crystal structure and primary particle size, the powder was pressed into a certain shape and analyzed by X-ray diffraction (XRD, Hitachi, Japan) with $\mathrm{Cu}$ $\mathrm{K} \alpha(\lambda=1.54 \AA)$ radiation at a scanning speed of $5 \% \mathrm{~min}$. The morphologies of the synthesized nanoparticles were analyzed by field emission scanning electron microscope (FE-SEM, JEOL, Japan); the crystallinity was evaluated with selected area diffraction (SAED) and its individual particle sizes were confirmed by transmission electron microscope (TEM, JEOL, Japan). Furthermore, the powder was dispersed in ethanol and sonicated for $20 \mathrm{~min}$; subsequently, it was dropped onto a $\mathrm{Cu}$ grid and dried in a chamber at $80{ }^{\circ} \mathrm{C}$ for 24 hours.

\section{RESULTS AND DISCUSSION}

As shown in Fig. 1 (a), SEM and XRD were performed to analyze the initially recycled $\mathrm{Li}_{2} \mathrm{SO}_{4}$ precursor obtained from
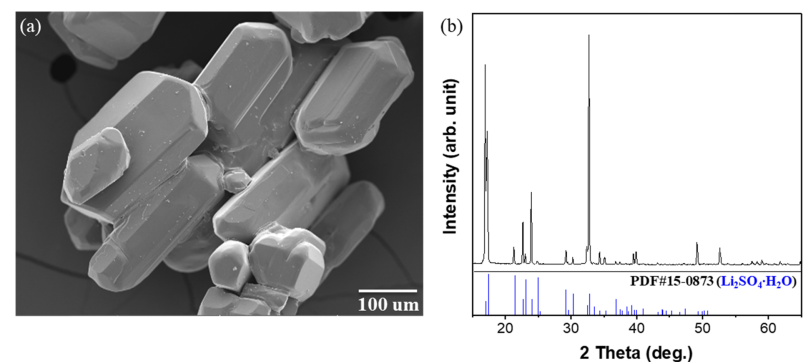

Fig. 1. $\mathrm{Li}_{2} \mathrm{SO}_{4}$ precursor analysis of (a) SEM image and (b) XRD peak

the Li-containing spent battery. According to the SEM image, the initial morphology of the $\mathrm{Li}_{2} \mathrm{SO}_{4}$ was a hexagonal prism structure with length in the range of $80.1 \sim 297 \mu \mathrm{m}$ and width in the range of $78.1 \sim 164 \mu \mathrm{m}$. The XRD pattern in Fig. 1 (b) identifies that it has a monoclinic $\mathrm{Li}_{2} \mathrm{SO}_{4}$ structure in accordance with the JCPDS 15-0873.

Various parameters were considered and tested to optimize the reaction conditions between $\mathrm{LiOH}$, which was synthesized using $0.01 \mathrm{~mol} \mathrm{Li}_{2} \mathrm{SO}_{4}$ with $0.01 \mathrm{~mol} \mathrm{Ba}(\mathrm{OH})_{2}$. These parameters were reaction temperature and time, as shown in Fig. 2 XRD. Fig. 2 (a) shows patterns of synthesized powders with different reaction times at RT.

$\mathrm{Li}_{2} \mathrm{CO}_{3}$ is known to have a lower solubility in water and reacts through an ion exchange mechanism at the limited surface area. However, other precursors that have a high solubility trigger the nucleation and growth mechanism; this leads to their complete conversion into a different crystal structure and morphology, as compared to the initial precursor [9,17]. Following this reaction, the hydrate precursor of $\mathrm{Li}_{2} \mathrm{SO}_{4}$ was completely transformed. A 2hour reaction at RT showed a low intensity of the $\mathrm{LiOH}$ and $\mathrm{BaCO}_{3}$ mixed phase. As the reaction time increased, not only did the $\mathrm{LiOH}$ peak increase, but $\mathrm{Li}_{2} \mathrm{CO}_{3}$ also newly emerged. $\mathrm{LiOH}$ can easily be transformed into $\mathrm{Li}_{2} \mathrm{CO}_{3}$ when it is heated above $100{ }^{\circ} \mathrm{C}$ in ambient air due to its characteristic nature of absorbing $\mathrm{CO}_{2}$ [19].

In the case of $\mathrm{BaCO}_{3}$, synthesized $\mathrm{BaSO}_{4}$ was removed by filtration following the reaction equation; this was due to its low solubility in water, which indicated that the unreacted initial $\mathrm{Ba}(\mathrm{OH})_{2}$ precursor was transformed. Characteristics similar to that of $\mathrm{LiOH}$ were also observed in $\mathrm{Ba}(\mathrm{OH})_{2}$. It could be easily observed reacting with $\mathrm{CO}_{2}$ in air when it was 

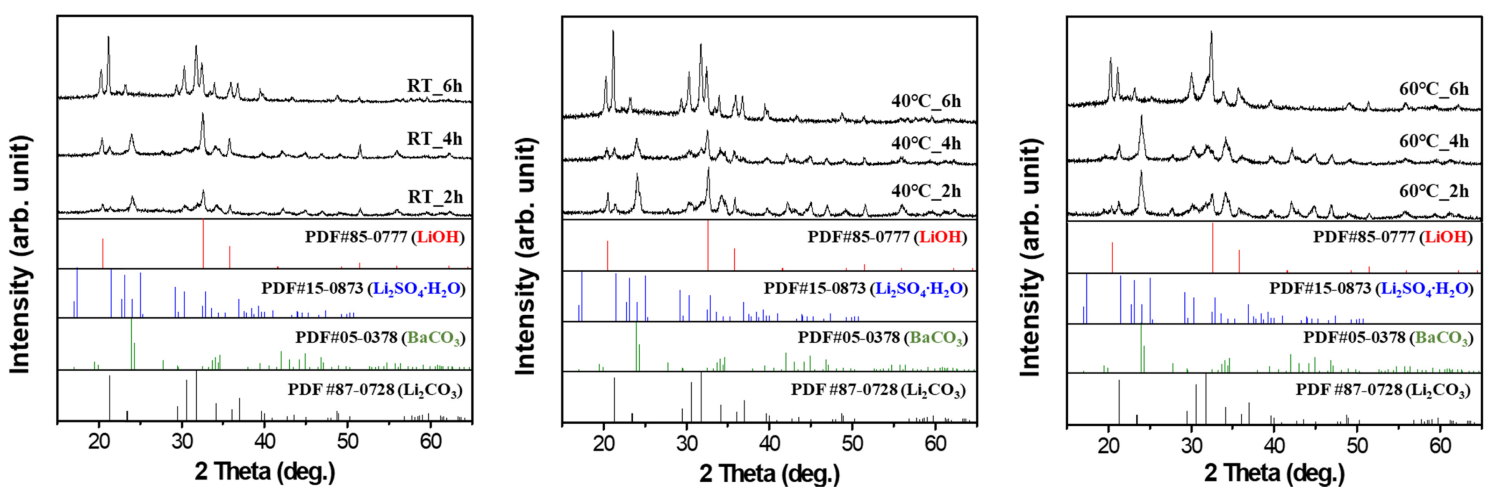

Fig. 2. XRD analysis of different temperature and reaction time (a) room temperature (b) $40^{\circ} \mathrm{C}$ and (c) $60^{\circ} \mathrm{C}$

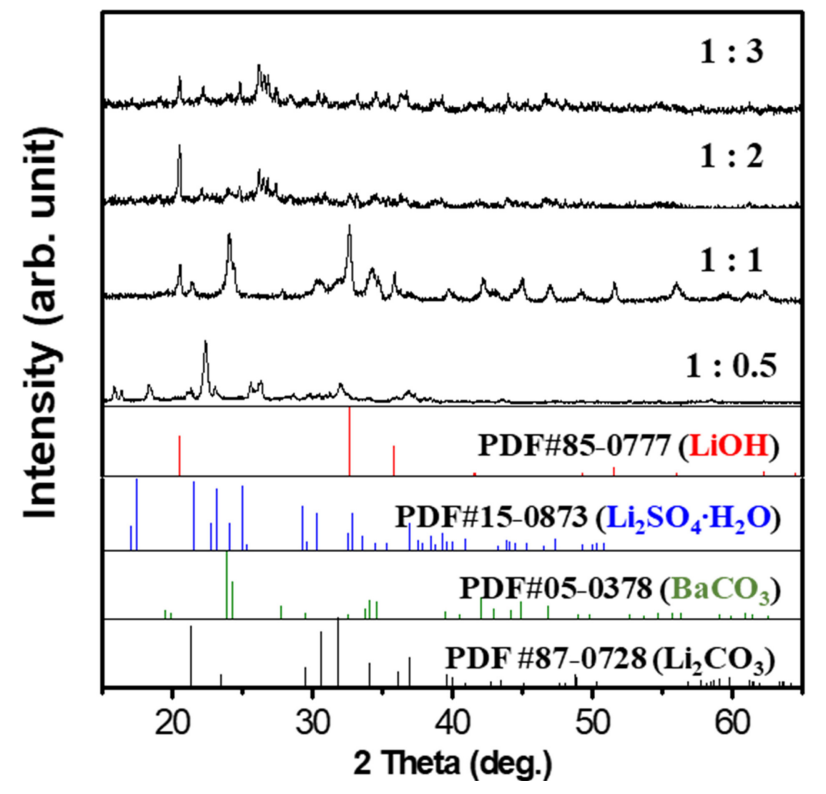

Fig. 3. XRD analysis of synthesized nanoparticles with different precursor ratio

heated between $40 \sim 90{ }^{\circ} \mathrm{C}[18]$. Fig. 2 (b) shows the reaction at $40^{\circ} \mathrm{C}$ with different reaction periods. Even though the reaction time was short, it was observed that $\mathrm{LiOH}$ was synthesized with high intensity. However, as the time increased, it also transformed into $\mathrm{Li}_{2} \mathrm{CO}_{3}$, showing a tendency similar to that observed under RT conditions.

At the reaction temperature of $60{ }^{\circ} \mathrm{C}$, a lower peak of $\mathrm{LiOH}$ was observed and $\mathrm{Li}_{2} \mathrm{CO}_{3}$ emerged at an earlier stage. This can be explained by the fact that the conversion efficiency of the precursor significantly depends on the reaction temperature. The precipitation process with higher temperature promotes faster particle growth synthesis. This is due to increasingly active ions in solutions with more highly mobile ionized precursors. Through a series of experiments, the optimum conditions for $\mathrm{LiOH}$ preparation was then determined to be $40{ }^{\circ} \mathrm{C}$ for a reaction time of 2 hours.

In order to understand the effect of precursor concentration on the synthesis of $\mathrm{LiOH}$, the $\mathrm{Ba}(\mathrm{OH})_{2}$ ratio was controlled between $1 / 0.5 \sim 1 / 3$ when fixing the $\mathrm{Li}_{2} \mathrm{SO}_{4}$ concentration. Fig. 3 shows the XRD patterns with different precursor ratios. According to this analysis, at a lower ratio $\mathrm{Ba}(\mathrm{OH})_{2}$ produced $\mathrm{BaSO}_{4}$, which was removed through filtration. However, the intermediate crystal structure of lithium hydroxide sulfate was not removed ( $\left.3 \mathrm{LiOH}-\mathrm{Li}_{2} \mathrm{SO}_{4}\right)$, and was separately identified by JCPDS card no. 32-0598. When the $\mathrm{Ba}(\mathrm{OH})_{2}$ ratio increased above $1 / 2, \mathrm{LiOH}$ was produced. Moreover, unreacted $\mathrm{Ba}(\mathrm{OH})_{2}$ with its high solubility penetrated the filter and remained in solution, which after evaporation showed a $\mathrm{LiOH}$ and $\mathrm{Ba}(\mathrm{OH})_{2}$ mixed crystal structure. Thus, for the optimum conditions, a precursor ratio of $1: 1$ was chosen.

Generally, the precipitation process is a one-step reaction that easily converts into the objective precipitant. However, the low conversion efficiency of the $\mathrm{Li}_{2} \mathrm{SO}_{4}$ precursor impedes this reaction, as previously shown in Fig. 2. For $\mathrm{Li}_{2} \mathrm{CO}_{3}$, to completely transform the precursor into $\mathrm{LiOH}$ and enhance efficiency, we precipitated it through a two-step reaction. The optimum conditions for the synthesis were a precursor ratio of $1: 1$, a temperature of $40{ }^{\circ} \mathrm{C}$ and a 2 hour reaction condition.

In Fig. 4, the XRD results show the peak of the two-step synthesized precipitant after filtration. $\mathrm{LiOH}-\mathrm{H}_{2} \mathrm{O}$ and $\mathrm{BaCO}_{3}$ co-exist in the precipitant, which also showed tendencies similar to the one-step precipitation method. 


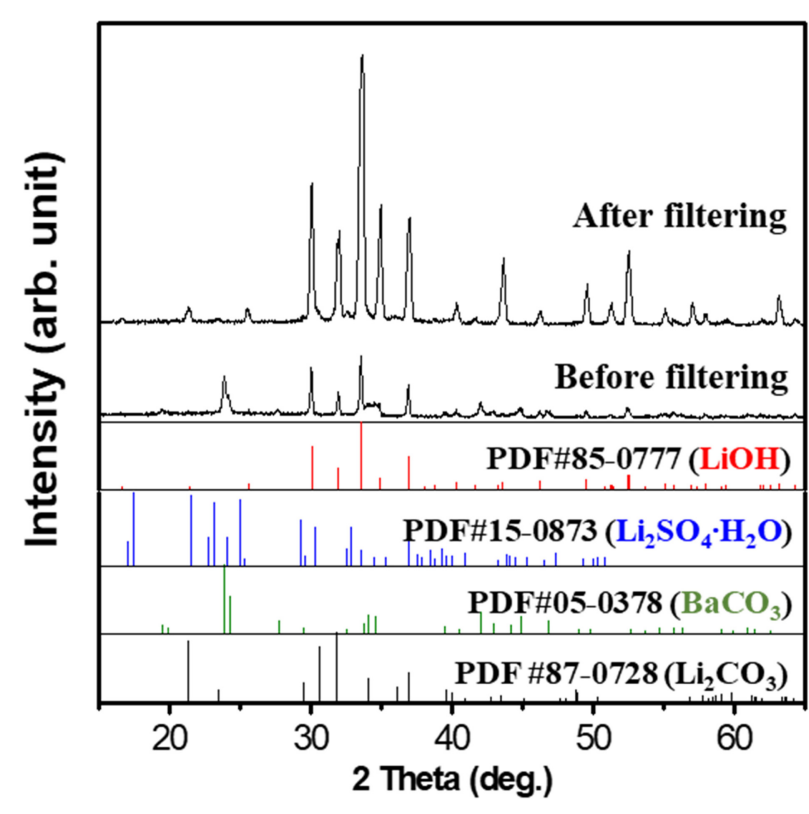

Fig. 4. XRD analysis of two-step precipitation method and comparison of filtering process

However, the huge difference between the reactions is that insoluble $\mathrm{BaCO}_{3}$ and soluble $\mathrm{LiOH}-\mathrm{H}_{2} \mathrm{O}$ are the primary ingredients, without any $\mathrm{Li}_{2} \mathrm{CO}_{3}$, which was observed in the one-step precipitant.

Accordingly, the synthesized powder was dissolved in D.I water and filtered again. According to the XRD data in Fig. 4 after filtering $\mathrm{LiOH}-\mathrm{H}_{2} \mathrm{O}$ was finally produced without any impurities.

The morphology and crystallinity of the $\mathrm{LiOH}$ nanoparticles depends on the evaporation temperature, and this was investigated under various conditions between $70 \sim$ $90{ }^{\circ} \mathrm{C}$ using SEM analysis, as shown in Fig. 5. According to the images in Fig. 5 (a), at an evaporation temperature of $70{ }^{\circ} \mathrm{C}$, uniformly distributed nanoparticles with a size of 35.8 \pm 9.77 were formed following the slow nucleation and growth process. When the temperature increased to $90{ }^{\circ} \mathrm{C}$, $\mathrm{LiOH}$ started to agglomerate and was grown with an irregularly mixed morphology of nanorods and pyramid-like structures with widths of $52.0 \pm 12.4$ and lengths of $194 \pm$ 14.7, as can be seen in Fig. 5 (b). Thus, the evaporation temperature of $70^{\circ} \mathrm{C}$ was chosen as optimum, for its uniformity and high surface area.

XRD and SEM analysis was conducted for the filtered precipitants after the two-step precipitation reaction, to
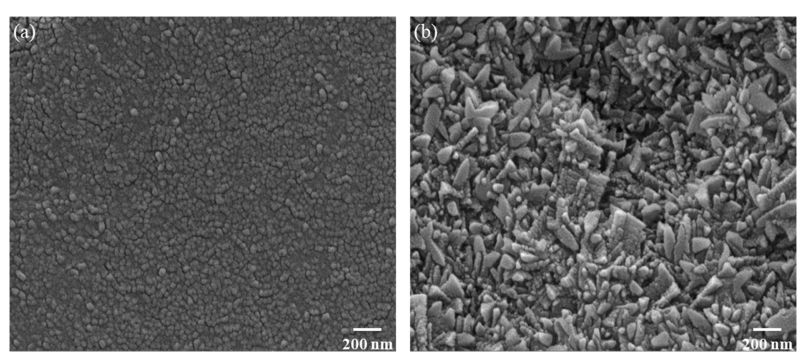

Fig. 5. SEM images of synthesis $\mathrm{LiOH}$ at different evaporation temperature (a) $70^{\circ} \mathrm{C}$ and (b) $90^{\circ} \mathrm{C}$
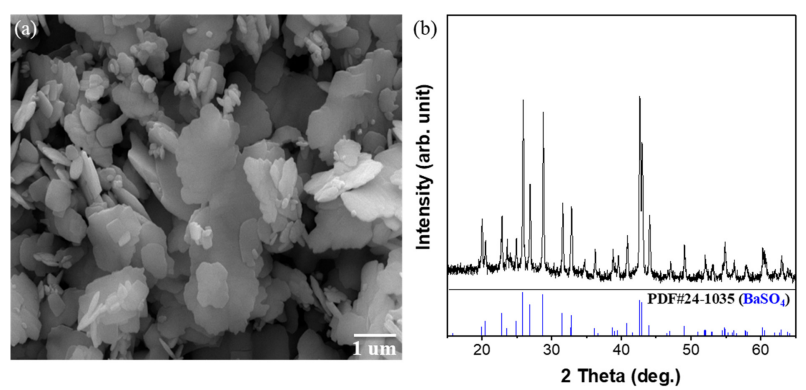

Fig. 6. Filtered precipitates after reaction (a) SEM images and (b) XRD analysis

determine conversion efficiency and the existence of other impurities. In the SEM image in Fig. 6 (a), irregular sheets with some stacked structures can be seen. In the XRD analysis in Fig. 6 (b), pure $\mathrm{BaSO}_{4}$ was produced (JCPDS card no. 24-1035) with no other impurities. This confirmed the optimum precursor ratio.

The as-prepared $\mathrm{LiOH} \cdot \mathrm{H}_{2} \mathrm{O}$ nanoparticles were thermally treated to remove any hydrates and were transformed at $100{ }^{\circ} \mathrm{C}$ for 2 hour in an atmosphere of $\mathrm{N}_{2}$ into $\mathrm{LiOH}$. Above $100{ }^{\circ} \mathrm{C}$, the annealing process promotes $\mathrm{CO}_{2}$ adsorption and $\mathrm{LiOH}$ easily converts into $\mathrm{Li}_{2} \mathrm{CO}_{3}$, which can be identified in Fig. 2.

In Fig. 7, the XRD pattern after calcination occurred reveals that the initial monoclinic phase of $\mathrm{LiOH}-\mathrm{H}_{2} \mathrm{O}$ (JCPDS card no. 76-1037) transformed into a pure tetragonal structure of LiOH (JCPDS card no. 85-0777) with high crystallinity. By comparing the XRD peaks before and after calcination, no changes, such as broader or sharper phenomena, were observed. This means that the hydrate bond was removed by heat treatment without inducing any differences in the size of the crystallites of the two samples, leaving $\mathrm{Li}$ with a purity of $99.6 \%$, as shown in Table 1 by 

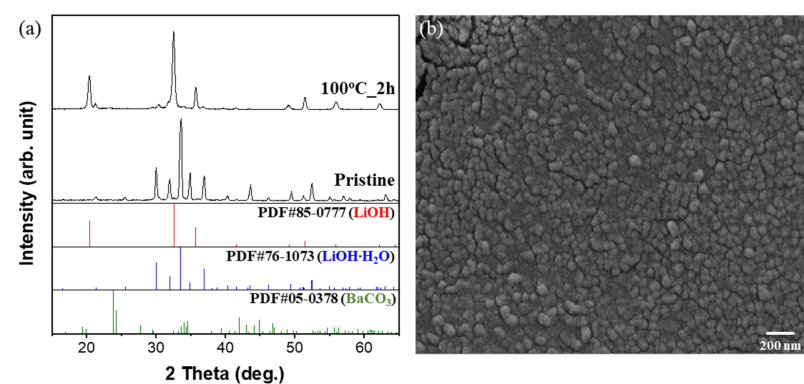

Fig. 7. XRD analysis of calcination effect on $\mathrm{LiOH} \cdot \mathrm{H}_{2} \mathrm{O}$ nanoparticles at condition of $100^{\circ} \mathrm{C}$ for $2 \mathrm{~h}$ (a) XRD analysis and (b) SEM image

Table 1. Chemical composition of synthesized LiOH through twostep precipitation

\begin{tabular}{cc}
\hline Element & Concentration of LiOH solution $(\mathrm{ppm})$ \\
\hline $\mathrm{Li}$ & 2541.34 \\
\hline $\mathrm{Na}$ & 9.71 \\
\hline $\mathrm{Fe}$ & 1.2 \\
\hline $\mathrm{Ca}$ & - \\
\hline $\mathrm{Mg}$ & - \\
\hline $\mathrm{Co}$ & - \\
\hline $\mathrm{Ni}$ & - \\
\hline $\mathrm{Li}$ purity & $99.6 \%$
\end{tabular}

ICP analysis.

TEM analysis was performed to identify the crystalline structure of the $\mathrm{LiOH}$ nanoparticles at total precursor ratio of 1:1 with two-step precipitation and an evaporation temperature of $70^{\circ} \mathrm{C}$. Fig. 8 (a) shows low magnification images of the $\mathrm{LiOH}$ nanoparticles. They appear as regularly distributed nanoparticles in accordance with the SEM images in Fig. 7. In the high magnification image in Fig. 8 (b), individual primary particles were agglomerated into nanoparticles during the nucleation and growth process.

For further analysis, HRTEM, as seen in Fig. 8 (c) was performed to elucidate the crystalline structure of the $\mathrm{LiOH}$. Lattice spacings in the $\mathrm{LiOH}$ nanoparticles were found to be $0.22 \mathrm{~nm}$ and $0.15 \mathrm{~nm}$, which correspond to the (310) and (002) planes in tetragonal $\mathrm{LiOH}$, respectively [20]. The specific lattice constant of the $\mathrm{LiOH}$ nanoparticle was confirmed by the dot shaped SAED patterns of the (310), (002), (621) and (060) planes, which are consistent with a single crystalline nature.
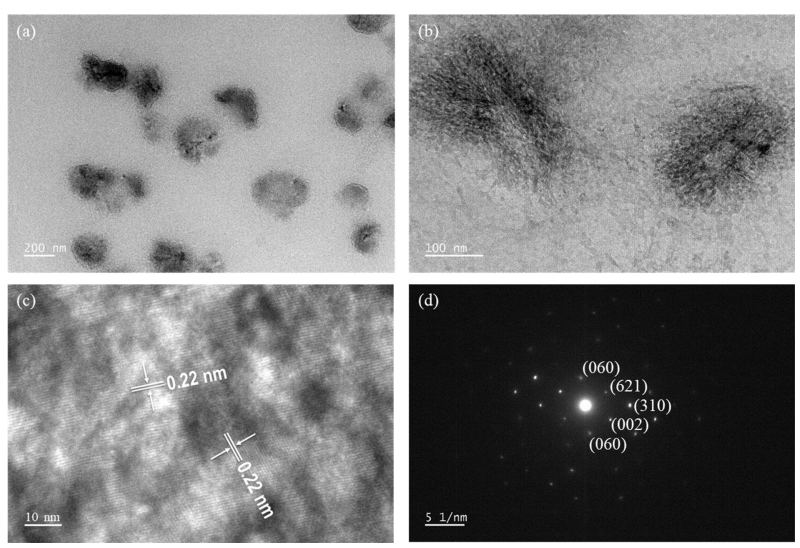

Fig. 8. TEM images of synthesized LiOH nanoparticles from twostep precipitation method (a) low resolution, (b) high resolution, (c) lattice constant and (d) SAED pattern

\section{CONCLUSIONS}

In order to produce uniform $\mathrm{LiOH}$ nanoparticles with high conversion efficiency, a two-step precipitation method was used. For the reaction conditions, a specific precursor ratio of 1:1 was chosen, and the hydroxyl containing the precursor was divided into halves. First, a precursor ratio of 1:0.5 was chosen to react for $60 \mathrm{~min}$ at a solution temperature of $40^{\circ} \mathrm{C}$, and subsequently filtered to remove any precipitates. After filtration, half of its hydroxyl precursor was placed into the filtered solution and was reacted under the same conditions. After the reaction, the precipitated powder was filtered, and the solution was evaporated at the solution temperature of $70{ }^{\circ} \mathrm{C}$ until a white powder emerged. In order to break hydrate bonds in the $\mathrm{LiOH}$, thermal treatment was performed at a low temperature of $100{ }^{\circ} \mathrm{C}$ to prevent phase transformation by the adsorption of $\mathrm{CO}_{2}$. Using this method, we synthesized uniform nanoparticles with mean sizes of $35.8 \mathrm{~nm}$ and a highly purified $\mathrm{LiOH}$ tetragonal phase having $99.6 \%$ purity.

\section{ACKNOWLEDGEMENTS}

The authors would like to thank the support of the Korean Journal of Metal and Materials (KJMM) which is funded by the Ministry of Trade, Industry and Energy, Republic of Korea (No.:20185210100050). 


\section{REFERENCES}

1. S. Bhagat, J. Mol. Catal. A 244, 20 (2006).

2. T. Liu, Angew. Chem. Int. Ed. 56, 16057 (2017).

3. . M. Ticich, J. Chem. Ed. 88, 189 (2011).

4. K. J. Kim, Sep. Sci. Technol. 43, 420 (2008).

5. . Liu, Science 350, 530 (2015).

6. . Liu, Angew. Chem. Int. Ed. 129, 16273 (2017).

7. A. D. Ryabtsev, Russ. J. Appl. Chem. 77, 1108 (2004).

8. C. Jiang, Ind. Eng. Chem. Res. 53, 6103 (2014).

9. K.-J. Kim, Sep. Sci. Technol. 43, 420 (2008).

10. B. Yuan, Particuology 34, 97 (2017).
11. Y. J. Song, Korean J. Met. Mater. 56, 10 (2018).

12. L. Li and J. Ge, Waste Management 30, 2615 (2010).

13. O. A. Fouad, J. Anal. Appl. Pyrol. 78, 65 (2007).

14. S. M. Shin, Hydrometallurgy 79, 172 (2005).

15. G. Dorella, J. Power Sources 170, 210 (2007).

16. K. J. Kim, Sep. Sci. Technol. 43, 420 (2008).

17. B. Yuan, Particuology 34, 97 (2017).

18. G. E. Kalbus, J. Chem. Ed. 83, 910 (2006).

19. Y. Sun, Cryst. Res. Technol. 47, 437 (2012).

20. S. Y. Joo, Journal of the Korean Institute of Resources Recycling 28, 60 (2019). 